\title{
Desconcentração econômica e atratividade regional no estado do Rio de Janeiro entre 2000 e 2010
}

\author{
Helcio de Medeiros Junior ${ }^{1}$
}

\begin{abstract}
Resumo
O estado do Rio de Janeiro passou por mudanças a partir dos últimos vinte anos do século passado que promoveram alterações no contexto econômico e populacional fluminense, fruto da reorientação espacial dos investimentos. Em razão disso, a dinâmica populacional passou a privilegiar regiões receptoras dos investimentos e limítrofes a elas, como alternativas de moradia e inserção laboral. Segundo os indicadores da dinâmica econômica e do mercado de trabalho entre 2000 e 2010, ocorreram melhorias nas regiões com características industriais, e/ou limítrofes a elas, principalmente na Norte Fluminense, do Médio Paraíba e das Baixadas Litorâneas, decorrentes dos desdobramentos dos investimentos, com ênfase nas cidades-núcleo das duas primeiras, Macaé e Porto Real. Nas regiões mencionadas, os mercados de trabalho geraram postos de trabalho que absorveram a maioria dos migrantes que a atratividade econômica proporcionou. A partir do conjunto dos indicadores avaliados, no entanto, a região Norte Fluminense despontou como aquela que consolidou sua condição de segunda maior do estado do Rio de Janeiro, devido principalmente à predominância da atividade industrial.
\end{abstract}

Palavras-chave: dinâmica econômica; economia regional; mercado de trabalho.

\begin{abstract}
The state of Rio de Janeiro went by changes starting from the last twenty years of last century that promoted alterations in the economical context and population fluminense, fruit of the space reorientation of the investments. In reason of that, the population dynamics started to privilege receiving areas of the investments and bordering to them, as home alternatives and insert laboral. According to the indicators of the economical dynamics and of the labor market between 2000 and 2010, they happened improvements in the areas with characteristics industrial, and bordering to them, mainly in the Norte Fluminense, of Médio Paraíba and of the Baixadas Litoâneas, current of the unfoldings of the investments, with emphasis in the city-nucleus of the first two, Macaé and Porto Real. In the mentioned areas, the labor markets generated workstations that absorbed most of the migrants that the economical attractiveness provided. Starting from the group of the appraised indicators, however, the Norte Fluminense area blunted as that that consolidated her condition of second larger of the state of Rio de Janeiro, owed mainly to the predominance of the industrial activity.
\end{abstract}

\footnotetext{
${ }^{1}$ Economista, Mestre em Economia Empresarial, Doutor em Planejamento Urbano e Regional e pesquisador do LESTE-IPPUR/UFRJ;e-mail: hmedeirosjunior@gmail.com.
} 
Key words: economical dynamics, regional economy, labor market

\section{Introdução}

O estado do Rio de Janeiro passou por mudanças ao longo do século XX, considerando, principalmente, sua trajetória a partir dos anos 30. A partir dos últimos vinte anos do século passado, ocorreram importantes alterações no contexto econômico e populacional fluminense, fruto da reorientação espacial dos investimentos, que resultou, por um lado, em nova configuração regional da atividade econômica, e por outro, na ascensão da extração mineral como segmento mais dinâmico da indústria. A partir de então, e em razão da atratividade promovida por essa configuração regional alternativa, frações do território fluminense passaram a apresentar perdas e ganhos populacionais, e a dinâmica migratória passou a privilegiar novas áreas como alternativas de moradia e de inserção laboral.

Ao longo da primeira década do presente século observou-se, de maneira geral, a mesma orientação regional dos investimentos, privilegiando em sua maioria as mesmas áreas anteriormente receptoras, além da Região Metropolitana do Rio de Janeiro, em regiões que vem se caracterizando como novos polos. Este comportamento levou a que, as regiões do Médio Paraíba e a Norte-Fluminense, mantivessem ou consolidassem a condição de maior atratividade populacional e de negócios, devido a sua proeminência industrial, bem como as Baixadas Litorâneas e a Costa Verde e apresentassem maior dinamismo econômico.

Para alcançar os objetivos a que se propõe, o presente texto se estrutura em quatro sessões, além desta introdução, tendo a segunda uma breve revisão histórica do desenvolvimento regional fluminense, considerações sobre os investimentos regionais e a centralidade do investimento como componente da demanda agregada e da atratividade migratória decorrente. A terceira sessão exporá as dinâmicas, demográfica e econômica, regionais na primeira década do presente século, fazendo considerações sobre a evolução regional à luz dos indicadores utilizados, com ênfase naquelas em que as inversões produtivas vêm mudando o território, e, a quarta e última sessão trará elementos à guisa de conclusão. 


\section{Do fim do século passado ao início deste: desconcentração econômica fluminense, investimento, e mobilidade populacional}

O estado do Rio de Janeiro possui 92 (noventa e dois) municípios, agregados em oito regiões de governo, segundo a Fundação CEPERJ (Mapa 1). Apesar de alterações terem sido introduzidas ao longo dos anos na composição dos municípios, em algumas regiões (alguns passaram a pertencer à outra região, casos de Itaguaí e Maricá), na organização regional atual se basearão as análises ao longo do texto com as adaptações devidas.

\subsection{Evolução econômica regional fluminense: interiorização e permanências}

A formação econômica do território fluminense esteve muito ligada à cidade do Rio de Janeiro até o início do século XX, tendo sido ela a principal referência do Império e da República, graças, predominantemente, à recepção de investimentos públicos e importância política, até que se desse a transferência da capital para o planalto central em 1960. Até aproximadamente os anos 20, por outro lado, foi a atividade manufatureira que garantiu ao estado do Rio de Janeiro a condição de principal economia industrial do país, perdida nos anos seguintes devido à crise cafeeira e aos efeitos nocivos da Primeira Guerra Mundial, que levaram ao aumento dos custos e à perda de competitividade para a indústria paulista (SILVA, 2004; MELO; CONSIDERA, 1986). À mesma época, São Paulo vivenciava a industrialização brasileira de maneira diferente, a partir da participação de investimentos privados e da entrada de capitais externos, diversificando seu parque produtivo e orientando-o para setores mais novos e de elevado conteúdo tecnológico, levando a que a indústria fluminense passasse a assumir uma condição subordinada à paulista (MELO; CONSIDERA, 1986). Como resultado desta mudança, nos anos seguintes a economia fluminense passou a crescer a um ritmo menor do que a nacional e a paulista, caracterizando assim, a passagem para uma posição relativa inferior (SILVA, 2004). 


\section{Mapa 1}

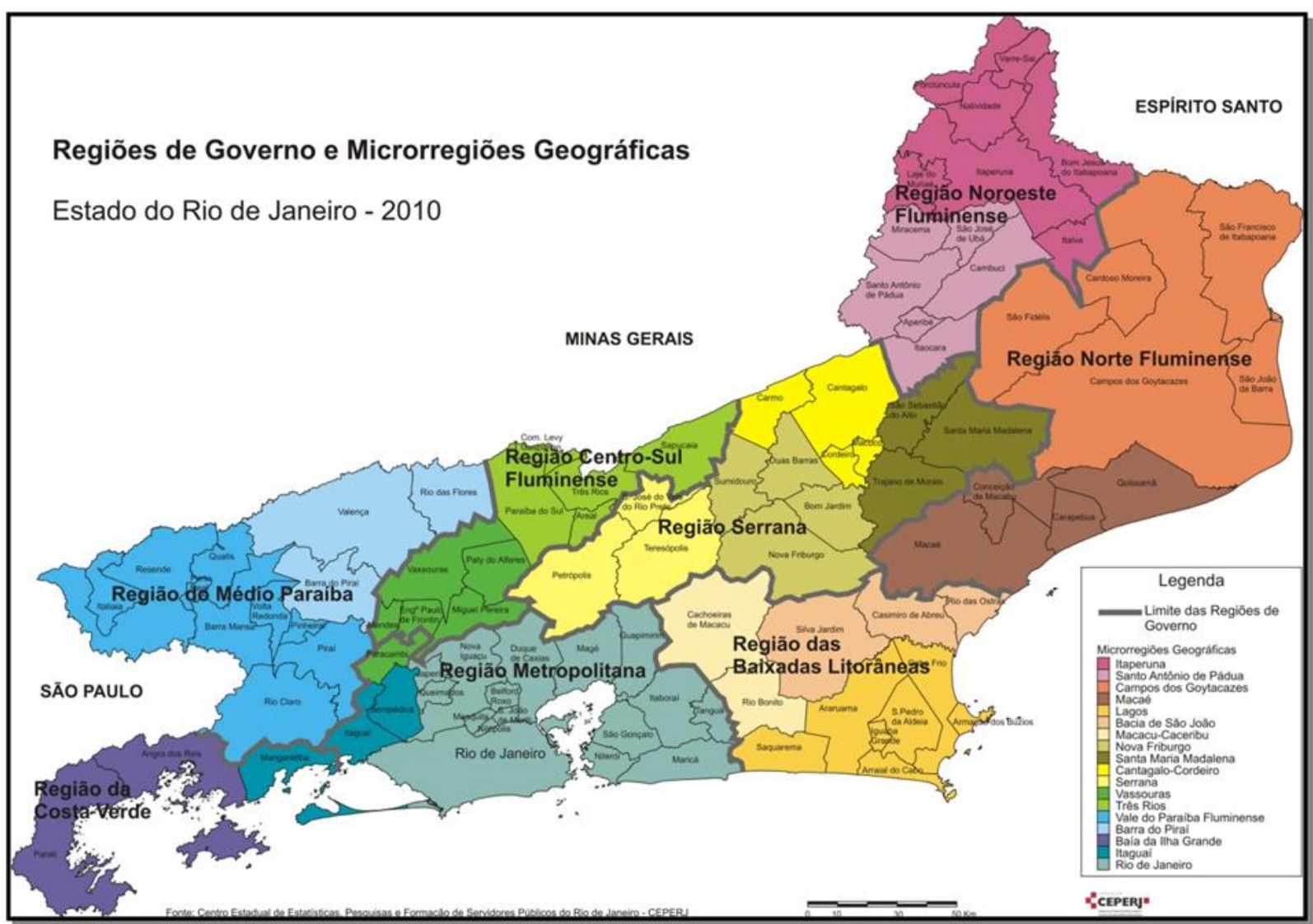

Fonte: Fundação CEPERJ, 2011

Nos anos seguintes, entre 1930 e 1980, mudanças importantes ocorreram para configurar, regionalmente, o que atualmente se observa. No período mencionado, considerado como da industrialização brasileira, combinaram-se alterações significativas na demografia e economia fluminenses. Em termos populacionais, ocorreu o aumento das taxas de crescimento médio anuais no estado e da participação populacional fluminense no total nacional, com destaque para a elevada migração para a Região Metropolitana, aumentando sua taxa de urbanização. As mudanças migratórias deveram-se, por um lado, à derrocada agrícola sofrida pela atividade cafeeira, e por outro, às alternativas disponíveis no meio urbano metropolitano que, à época, possuíam maior diversidade econômica e melhores alternativas de absorção de mão de obra. Quanto às mudanças econômicas, acentuou-se a perda relativa de participação do PIB fluminense perante o nacional, passando de $21 \%$ em 1939 para $13 \%$ em 1980, enquanto o peso do PIB paulista elevou-se de $31 \%$ para $38 \%$, no mesmo período (SILVA, 2004). 
Ao mesmo tempo em que estes processos ocorriam, importantes intervenções logísticas se efetivaram, levando a uma nova fase da industrialização do estado. A partir da década de 1950, políticas federais de integração das áreas industriais mais significativas levaram a que investimentos em rodovias iniciassem uma nova fase da industrialização fluminense, com três eixos, partindo da cidade do Rio de Janeiro. Em 1952 foram inauguradas a Avenida Brasil e o trecho sul da Avenida Presidente Dutra (BR-116), o que permitiu a industrialização ao longo da principal via carioca de ligação entre o Centro e a Zona Oeste e a consolidação dos segmentos siderúrgico e metalúrgico, no Médio Vale do Paraíba, bem como alavancou a ocupação industrial ao longo da Dutra, nos municípios de São João de Meriti e Nova Iguaçu, na Baixada Fluminense. Num segundo eixo, associado à Rio-Juiz de Fora (BR-040), foram revitalizados os segmentos de laticínios, alimentos e metal-mecânico, após o município de Petrópolis, bem como mais próximo à cidade do Rio de Janeiro, instalou-se a Refinaria Duque de Caxias (REDUC), dinamizando segmentos ligados ao setor químico carioca. Por fim, o terceiro eixo ligou, a partir da década de 1970, a capital da Guanabara ao norte do estado, com a extensão da BR-101 pela Ponte Rio Niterói (1974), beneficiando a expansão das regiões das Baixadas Litorâneas (segunda residência e veraneio) e do Norte-Fluminense (exploração petrolífera na Bacia de Campos), e ao sul, com a dinamização da região da Costa Verde (ampliação do porto da Petrobras e instalação da usina termonuclear de Furnas e do estaleiro Verolme, em Angra dos Reis). Se, por um lado, a estruturação dos eixos mencionados representou maior alternativa para o aparecimento de novas regiões econômicas no estado do Rio de Janeiro, por outro consagraram a dependência de investimentos federais e, por suposto, a ausência de alternativas a eles. Da mesma forma, não foram capazes de gerar centros regionais estruturados que permitissem reduzir a vinculação ao núcleo metropolitano (OLIVEIRA, 2008).

Em razão da dependência de investimentos federais, as dificuldades pelas quais a economia nacional passou no período conhecido como a década perdida (anos 1980) levaram a um quadro de semiestagnação econômica. Agregados ao período anterior, no entanto, entre 1930-1990, o que se presenciou no estado do Rio de Janeiro foram movimentos caracterizados como de "crescimento e modernização, com perda de importância relativa" (SILVA, 2012, p. 41). Se por um lado a economia fluminense 
seguiu a trajetória de expansão e modernização produtiva apresentada no nível nacional, por outro evoluiu a taxas inferiores às de outras unidades federativas, resultando num processo gradativo de perda de participação econômica.

A partir dos anos 1990, regionalmente, o que se viu foi a permanência da macrocefalia metropolitana (NATAL, 2005; SILVA, 2012), tendo a Região Metropolitana do Rio de Janeiro (RMRJ) mantido parte relevante da estrutura industrial e, em grande medida, o terciário fluminense, bem como o fortalecimento de duas regiões que emergiram a partir da estruturação dos eixos viários, anteriormente mencionados: Médio Paraíba e Norte Fluminense.

\subsection{Investimentos regionais neste início de século}

O estado do Rio de Janeiro recebeu investimentos ao longo da primeira década do presente século, de cerca de $\mathrm{R} \$ 100$ bilhões, e de acordo com levantamentos recentes, as inversões programadas para o período 2010-2012 alcançam cerca de $\mathrm{R} \$ 43$ bilhões, para a instalação de refinarias de petróleo, construção de navios petroleiros, de automóveis e de complexo portuário no interior do estado, que abrangem os segmentos de construção naval, transporte/logística, petroquímico, energia, borracha $\mathrm{e}$ desenvolvimento urbano (FUNDAÇÃO CEPERJ, 2012). Apesar de ainda possuir elevada concentração econômica na Região Metropolitana do Rio de Janeiro, que também foi privilegiada com a recepção dos citados investimentos, manteve-se a desconcentração para o interior, motivada, principalmente, pelas atividades do setor petrolífero da Bacia de Campos, que graças à demanda internacional pela commoditie, motivou a criação do Complexo Petroquímico do Rio de Janeiro-COMPERJ, em Itaboraí, cuja divulgação se deu em 2006. Ainda na RMRJ, está em curso a construção do Arco Rodoviário que ligará o COMPERJ a Itaguaí, o que representará importante alternativa viária e de integração da cadeia petrolífera.

Na região do Médio Paraíba se consolidam os segmentos siderúrgico e metalmecânico, tendo como cidades mais importantes: a) Volta Redonda e Barra Mansa, beneficiadas pela presença da Companhia Siderúrgica Nacional (CSN), empresa, cuja influência alcança o Porto de Sepetiba em Itaguaí; b) Resende, que serve de importante centro de consumo para os trabalhadores da indústria automobilística e onde se localiza 
a Volkswagen, e; c) Porto Real, na qual se instalou a PSA Peugeot-Citröen, e em breve, receberá a Michelin e a Nissan. Já na região do Norte-Fluminense, as atividades relacionadas à extração mineral elevaram Macaé a um segundo centro regional, tendo ainda investimentos em energia em Campos dos Goytacazes (Chevron e OGX) e São João da Barra (Usina Termelétrica do Açu), bem como nesta também há inversões em transporte/logística (Complexo Portuário do Açu). Além das três regiões mencionadas, apenas na região da Costa Verde há investimentos de ampliação da usina nuclear de Angra dos Reis, enquanto nas demais, não há menção a inversões.

\subsection{Investimentos e seus efeitos no território}

Pelo que se observa, a reestruturação regional fluminense tem se baseado em grande medida no setor secundário, com destaque nos segmentos metal-mecânico e automobilístico no Médio Paraíba, e extrativo mineral no Norte-Fluminense, e no investimento como o motor da ampliação da atividade econômica. A centralidade do investimento para a atividade econômica foi defendida por Keynes (1988), que o considerava o fator dinâmico da economia, capaz de assegurar o pleno emprego e influenciar a demanda, haja vista que o fator responsável pela alteração do volume de emprego é a procura por mão de obra oriunda das empresas, que contratarão novos trabalhadores e realizarão inversões no sistema econômico na medida em que a eficiência marginal do capital (expectativa de lucros) for positiva. Kalecki (1985), de maneira assemelhada, sustentou que o nível de atividade econômica é estreitamente dependente dos investimentos, uma vez que se eles aumentarem, os níveis de atividade e emprego se elevarão, alimentando uma maior demanda por bens e serviços, e levarão a que os lucros dos capitalistas sejam maiores.

Adaptadas à escala regional, as contribuições de Keynes e Kalecki indicam que os sistemas econômicos locais (cidades), receptores dos investimentos, assistirão a transformações que se estenderão aos territórios que conformam seu entorno imediato, bem como com outras cercanias às quais se conectem. A mudança decorrente, de natureza multidimensional (social, econômica, ambiental, política etc.), dependerá do tipo e da escala do investimento, em geral um enclave, haja vista que não surgem naturalmente e como resposta a um processo endógeno pregresso (PIQUET, 1993). Os 
efeitos mais claros e imediatos estão relacionados ao aumento das oportunidades de negócios e à mobilidade populacional, que, em decorrência, elevam as pressões nos mercados de trabalho dos territórios receptores. Com relação ao primeiro efeito, do aumento das oportunidades de negócios, a partir da necessidade de que novas atividades se desenvolvam em apoio ao empreendimento gerado pelo investimento, e da expansão da oferta de serviços no meio urbano, há um processo de diversificação econômica que aumenta a demanda por mão de obra (como explicado por Keynes e Kalecki) e as chances de ingresso no mercado de trabalho (OLIVEIRA, 2006a, 2006b), com provável elevação do nível de salários. Quanto ao efeito associado (mobilidade populacional), há evidências que a migração será mais provável na medida em que os trabalhadores sejam sensíveis aos diferenciais de renda, entre o destino e a origem (BORJAS, 2012), ressalvados aspectos relativos às suas condições pessoais (gênero, instrução, raça, cor etc.), que determinarão o nível de discriminação a que virão sofrer no destino, dada a segmentação do mercado de trabalho existente (SOUZA, 1978; LIMA, 1980).

As pressões de um maior contingente de força de trabalho sobre o mercado de trabalho local são inevitáveis, e o descasamento entre a oferta e a demanda por trabalho se refletirá em taxas de desemprego mais elevadas, na medida em que a dinâmica econômica não gere as vagas adicionais que absorvam os trabalhadores migrantes. Torna-se relevante, então, observar as mudanças pelas quais o mercado de trabalho local passou sua capacidade de reação e a condição da inserção dos trabalhadores.

\section{Dinâmicas regionais da atividade econômica, da população migrante e dos trabalhadores}

A fim de avaliar a dinâmica populacional e econômica das regiões do estado do Rio de Janeiro, bem como de seus efeitos sobre a inserção ocupacional dos trabalhadores nos mercados de trabalho, neste exercício far-se-á uso das informações: 1) dos Censos Demográficos de 2000 e 2010, com o fim de avaliar como evoluíram a população, a partir do número de pessoas residentes, e o mercado de trabalho regional, com base nas variáveis que caracterizam as condições de atividade $^{2}$ e de ocupação ${ }^{3}$ dos

\footnotetext{
2 As pessoas são classificadas, quanto à condição de atividade na semana de referência, em economicamente ativas e não economicamente ativas.
} 
residentes, e como se inserem, com base na posição na ocupação ${ }^{4}$ no trabalho principal; 2) do Valor Adicionado Fiscal ${ }^{5}$ (VAF) de 2000 e 2010, para observar a geração de renda local pela diferença entre os fluxos inter-regionais; 3) do Imposto sobre Circulação de Mercadorias e Serviços (ICMS) de 2000 e 2010, com o fim de observar o volume de negócios locais nas atividades comerciais e de serviços, abrangidos pelo imposto, sendo esta uma Proxy do nível da atividade econômica local; 4) da distribuição da remuneração em salários mínimos e do número de vínculos (ou postos de trabalho) existentes em 31/12 dos anos de 2000 e 2010, oriundos da Relação Anual de Informações Sociais (RAIS) do Ministério do Trabalho e Emprego (MTE), como indicadores do retorno do sistema econômico local às características dos trabalhadores, e de sua capacidade de resposta, via demanda por trabalho, e; 5) do Produto Interno Bruto (PIB) municipal do IBGE de 2000 e 2010, que expressa a capacidade de geração de riquezas dos sistemas econômicos locais.

Para a realização das comparações entre os anos mencionados, alguns cuidados foram tomados para que não se incorresse em deslizes, considerando-se questões: a) de natureza organizacional das informações, em razão das mudanças nos municípios de algumas regiões no período intercensitário, como mencionado na segunda sessão. Optou-se por alterar a distribuição municipal regional de 2000, adequando-a a existente em 2010, para fins de comparação; b) derivadas do uso de variáveis expressas em valor monetário, caso do VAF, do ICMS e do PIB, que ao serem confrontadas requereriam ajustes inflacionários nos valores de 2000, para que fossem comparáveis a $2010 \mathrm{em}$ termos "reais". Optou-se por não fazê-lo, apesar de ser comum em outras análises o uso de informações ajustadas (BRAGA, 2011), ou transformadas mediante índices de preço, tais como o IGP-DI e o IGP-M da FGV, ou o INPC e o IPCA do IBGE (NATAL, 2005). Por não serem índices que expressem cestas municipais de cidades/regiões que vêm passando por alterações significativas, utilizá-los representaria homogeneizar

\footnotetext{
${ }^{3}$ As pessoas são classificadas, quanto à condição de ocupação na semana de referência, em ocupadas e desocupadas.

${ }^{4}$ Os trabalhadores se inserem no mercado de trabalho nas condições de empregados com carteira de trabalho assinada, empregados militares e funcionários públicos estatutários, empregados sem carteira de trabalho assinada, conta própria, empregadores, não remunerados e trabalhadores na produção do próprio consumo.

5 O Valor Adicionado Fiscal é obtido através da diferença entre o valor das saídas de mercadorias e dos serviços e transporte e de comunicação prestados no seu território, e o valor das entradas de mercadorias e dos serviços de transporte e de comunicação adquiridos, em cada ano civil.
} 
realidades sociais e econômicas diferentes, assemelhando-as à área de maior peso na composição de cada um dos índices. Na medida em que não há índices de preços locais/regionais, nem variações de volume das variáveis expressas em valor, preferiu-se trabalhar com participações em corte transversal, confrontando-as nos dois momentos escolhidos, bem como proceder a análises conjuntas, com as evoluções obtidas a partir das variáveis reais: população e vínculos.

Ainda quanto às variáveis expressas em valor monetário, menção especial é devida ao uso inadvertido em variados textos do Produto Interno Bruto (PIB) municipal divulgado pelo IBGE, como variável para medir o "crescimento econômico" dos municípios. Considerando-se que: a) o crescimento econômico entre dois momentos do tempo toma como base a série de índices de volume para sua aferição (disponíveis nas séries das contas nacionais e regionais); b) o valor do PIB resulta do produto entre o volume produzido e os preços médios para cada uma das atividades pesquisadas, e; c) a medição do PIB municipal existente representa um rateio para os municípios do valor do PIB da Unidade da Federação respectiva ${ }^{6}$, fica claro que tomar a razão entre momentos do tempo de c), ou seja, de dois valores, como se expressassem o que somente a) pode proporcionar, resulta em engano.

Para dar conta da ausência do indicador de volume na série do PIB municipal, em alguns estudos se "desconta" dos valores do PIB a variação dos preços pelo uso de índices gerais (IGP-DI/FGV, por exemplo), cuja composição não contempla a estrutura de preços das atividades econômicas locais. Na medida em que há especializações produtivas regionais, o uso de índices gerais de preço no deflacionamento dos valores do PIB municipal desconsidera a dinâmica particular destas regiões, gerando distorções consideráveis. Portanto, fins nobres podem gerar efeitos perversos. Cabe ponderar, enfim, que: a) no desenho atual o sistema estatístico nacional não oferece aos municípios informações que permitam calcular seu crescimento econômico, e; b) tomar o valor do PIB municipal como variável para medi-lo, não é aconselhável.

\footnotetext{
${ }^{6}$ Ver metodologia em www.ibge.gov.br.
} 


\subsection{Dinâmica econômica e populacional recente das regiões fluminenses}

A influência exercida pelos investimentos que tem sido feitos no território fluminense, desde o século passado, a nosso juízo, contribuíram para a evolução regional recente, seja em termos populacionais ou econômicos, haja vista o deslocamento e a chegada de novos residentes em cidades com a expectativa de maiores oportunidades laborais, em razão do dinamismo da atividade econômica.

Segundo o que já se observou anteriormente (MEDEIROS JUNIOR, 2012a, 2012b), as regiões de fora do núcleo metropolitano que vem se beneficiando de inversões e passaram a apresentar dinâmicas diferenciadas em relação às demais em seus sistemas econômicos locais, considerando-se a evolução do VAF e do ICMS (Tabela 1), foram as do Médio Paraíba e a Norte Fluminense ${ }^{7}$. Este comportamento, por um lado, é fruto da maturação dos investimentos na implantação e geração da cadeia de valor das atividades que as caracterizam: desde meados da década de 1990, como o início da instalação das montadoras de automóveis no Médio Paraíba, e meados da década de 1980, quanto à atividade petrolífera (SILVA, 2012). Por outro lado, também reflete os efeitos secundários de expansão das atividades econômicas de apoio e suporte à vida urbana, seja nos municípios-sede dos empreendimentos industriais (Resende e Porto Real no Médio Paraíba, e Macaé no Norte Fluminense), ou nas cidades do entorno, que se beneficiaram da proximidade com o centro produtor.

Em outras regiões, nas quais os indicadores não alcançaram o mesmo resultado, fatores específicos foram determinantes. É o caso das regiões das Baixadas Litorâneas e da Costa Verde, que apesar de serem atrativas para veraneio e segunda residência, apresentaram dinamismo de acordo com suas características particulares. Na região das Baixadas Litorâneas, que não tem sido alcançada por investimentos industriais e caracteriza-se por atividades de turismo e lazer, o aumento do volume de negócios (da participação no ICMS) deveu-se ao fato de ter sido a única que apresentou maior número de cidades com elevada taxa média de crescimento anual entre 2000 e 2010 , tendo como destaque Rio das Ostras (11,2\% ao ano) e Casimiro de Abreu (4,8\% a.a.), vizinhas a Macaé (região Norte Fluminense). Já, a região da Costa Verde, que

\footnotetext{
${ }^{7}$ Foram as que apresentaram ganhos de participação significativos em ambos os indicadores, tendo a região Centro-Sul Fluminense pequenos acréscimos.
} 
apresentou aumento na participação do VAF e cujo investimento decidido é o da ampliação da usina nuclear, tem na construção naval em Angra dos Reis e no terminal de minérios em Mangaratiba, alternativas econômicas ao turismo que oferece (MEDEIROS JUNIOR, 2012a, 2012b), e, portanto, na atividade econômica o fator de atração populacional.

Tabela 1

Participação do valor adicionado fiscal e do imposto sobre circulação de mercadorias e serviços nas Regiões de Governo do Estado do Rio de Janeiro - 2000/2010

\begin{tabular}{|c|c|c|c|c|}
\hline \multirow{2}{*}{ Estado e Regiões de Governo } & \multicolumn{2}{|c|}{ Valor adicionado fiscal (VAF) } & \multicolumn{2}{|c|}{$\begin{array}{l}\text { Imposto sobre circulação de } \\
\text { mercadorias e serviços (ICMS) }\end{array}$} \\
\hline & 2000 & 2010 & 2000 & 2010 \\
\hline Estado do Rio de Janeiro & 100.0 & 100.0 & 100.0 & 100.0 \\
\hline Região Metropolitana & 64.8 & 59.7 & 90.8 & 84.5 \\
\hline Região Noroeste Fluminense & 0.5 & 0.5 & 0.2 & 0.2 \\
\hline Região Norte Fluminense & 8.3 & 13.6 & 1.1 & 6.2 \\
\hline Região Serrana & 4.4 & 3.3 & 2.1 & 1.7 \\
\hline Região das Baixadas Litorâneas & 7.4 & 5.2 & 0.4 & 1.1 \\
\hline Região do Médio Paraíba & 9.7 & 11.1 & 5.0 & 5.5 \\
\hline Região Centro-Sul Fluminense & 0.5 & 1.0 & 0.2 & 0.5 \\
\hline Região da Costa Verde & 4.3 & 5.6 & 0.2 & 0.2 \\
\hline
\end{tabular}

Fonte: Fundação CEPERJ.

O deslocamento populacional decorrente da atratividade exercida pelo aumento dos negócios é um dos efeitos esperados nas regiões receptoras dos investimentos, ou que possuam outros atrativos para servirem de opção de residência. Segundo as informações do Censo Demográfico de 2010, excetuando-se a Região Metropolitana, mais populosa, que observou o maior acréscimo absoluto de pessoas residentes entre 2000 e 2010 (966.453 pessoas), as regiões das Baixadas Litorâneas (250.107) e Norte Fluminense (150.732) foram as que maior contingente agregaram aos residentes do começo do milênio. Em cada uma delas, as cidades que se destacaram no aumento populacional, em termos absolutos foram: Rio das Ostras (69.257) e Cabo Frio (59.399) nas Baixadas Litorâneas, e Macaé (74.267) e Campos dos Goytacazes (56.742) na Norte Fluminense. 
Parte do mencionado acréscimo populacional foi devido à migração ocorrida no período intercensitário de 2000 a 2010, bem como a população residente em 2000 já contemplava migrantes de anos anteriores. Considerando-se que as regiões das Baixadas Litorâneas e da Costa Verde vem apresentando taxas de crescimento médias anuais intercensitárias elevadas, desde o período 1980-1991 (MEDEIROS JUNIOR, 2012b), parte relevante do contingente populacional, recenseado em 2010 nestas regiões, seria de não naturais dos municípios que as compõem. Por outro lado, na medida em que o Censo Demográfico de 2010 discrimina o migrante pelo tempo de residência, é possível observar se, nos dez anos anteriores a ele, o acréscimo seria mais ou menos significativo, dado o estoque existente dos migrantes totais.

Tabela 2

População residente, migrantes intercensitários e totais, e participação dos migrantes intercensitários e totais na população residente das Regiões de Governo do Estado do Rio de Janeiro - 2010

\begin{tabular}{|c|c|c|c|c|c|}
\hline \multirow{2}{*}{ Estado e Regiões de Governo } & \multirow{2}{*}{$\begin{array}{l}\text { População } \\
\text { residente em } \\
2010\end{array}$} & \multicolumn{2}{|c|}{ Número de migrantes } & \multicolumn{2}{|c|}{$\begin{array}{l}\text { Participação dos migrantes na } \\
\text { população residente }(\%)\end{array}$} \\
\hline & & $\begin{array}{c}\text { Intercensi- } \\
\text { tários (1) }\end{array}$ & Totais (2) & $\begin{array}{l}\text { Intercensi- } \\
\text { tários }\end{array}$ & Totais \\
\hline Estado do Rio de Janeiro & 15989929 & 595050 & 2306712 & 3.4 & 14.4 \\
\hline Região Metropolitana & 11835708 & 429096 & 1836331 & 3.6 & 15.5 \\
\hline Região Noroeste Fluminense & 317493 & 10043 & 22130 & 3.2 & 7.0 \\
\hline Região Norte Fluminense & 849515 & 41028 & 64954 & 4.8 & 7.6 \\
\hline Região Serrana & 805627 & 17722 & 60436 & 2.2 & 7.5 \\
\hline Região das Baixadas Litorâneas & 810666 & 45782 & 104933 & 5.6 & 12.9 \\
\hline Região do Médio Paraíba & 855193 & 25531 & 94136 & 4.0 & 11.0 \\
\hline Região Centro-Sul Fluminense & 272227 & 7505 & 25818 & 2.8 & 9.5 \\
\hline Região da Costa Verde & 243500 & 18343 & 44076 & 7.5 & 18.1 \\
\hline
\end{tabular}

(1) Residentes naturais e não-naturais da Unidade da Federação com tempo ininterrupto de residência com menos de 10 anos.

(2) Residentes naturais e não-naturais da Unidade da Federação com tempo ininterrupto de residência com 10 anos ou mais.

Dentre as regiões que receberam migrantes no período intercensitário de 20002010, em termos absolutos, a Metropolitana foi a mais procurada (Tabela 2), por aproximadamente 429 mil pessoas, seguida da região das Baixadas Litorâneas (45,8 mil) e da Norte Fluminense (41,0 mil). O contingente que migrou para a região Metropolitana elevou para 1,8 milhão o estoque de pessoas naturais do estado do Rio de Janeiro, mas não de seus municípios, e de não naturais do estado do Rio de Janeiro 
(15,5\% da população total). O fato da migração intercensitária de 2000-2010 representar 3,6\% dos migrantes totais (próxima de um quarto do total) indica que a chegada de migrantes à região é um processo antigo.

Partindo da mesma premissa, regiões cuja participação dos migrantes intercensitários de 2000-2010, no total de migrantes, é relativamente baixa, podem indicar que motivações históricas foram mais determinantes para a composição do estoque do que processos mais recentes. É o caso das regiões Serrana $(29,3 \%$ do total de migrantes), do Médio Paraíba (27,1\%) e do Centro-Sul Fluminense (29,1\%). Apesar de apresentarem valores médios baixos, há municípios que as compõem que indicam processos em curso, que vem motivando a chegada de novos residentes, tais como: Bom Jardim $(88,1 \%)$, Trajano de Moraes $(77,1 \%)$ e Duas Barras $(56,5 \%)$ na região Serrana; Volta Redonda (46,8\%) e Porto Real (44,5\%) no Médio Paraíba, e; Vassouras $(46,8 \%)$ e Sapucaia $(45,3 \%)$ no Centro-Sul Fluminense.

O resultado das demais regiões, com participações de migração recente superiores a $40 \%$ do total, sugere que o deslocamento populacional é determinado pela continuidade de processos ou de outros, cuja motivação é mais recente. É o caso da região do Noroeste Fluminense, que teve o maior número de municípios com perda de população dentre as regiões no último Censo, mas na qual 45,4\% dos migrantes totais chegaram ao último período intercensitário. Nela se destacaram São José de Ubá $(74,2 \%)$ e Itaperuna $(58,0 \%)$ como principais cidades receptoras.

$\mathrm{Na}$ região das Baixadas Litorâneas, cuja população tem crescido continuamente, $43,6 \%$ dos migrantes totais chegaram entre 2000 e 2010, e, os municípios que se destacaram foram: Rio das Ostras (62,5\%), Armação dos Búzios (49,7\%), Cabo Frio e Casimiro de Abreu, ambos com 44,1\%, São Pedro da Aldeia (42,3\%) e Rio Bonito $(40,8 \%)$. Neste elevado número de cidades receptoras, caracterizadas por amenidades naturais e áreas turísticas, a migração indica uma mudança de segunda residência (veraneio) para primeira, além do fato de situarem-se próximo à região Norte Fluminense. Em outra região, que apresentou elevado crescimento nos últimos trinta anos, a Costa Verde, 41,6\% dos migrantes chegaram recentemente, e o município que se destacou em termos relativos foi Paraty (48,3\%), apesar de em termos absolutos Angra dos Reis ter agregado mais pessoas (13,3 mil), a maior cidade da região. 
Por fim, a região com o maior percentual de migrantes no período 2000-2010, em relação ao total, foi a Norte Fluminense $(63,2 \%)$, sendo, portanto, a que apresentou a maior motivação para o deslocamento populacional. Em termos absolutos, a cidade que mais recebeu novos habitantes foi Macaé (26,1 mil pessoas), seguida de longe por Campos dos Goytacazes (cerca de 10,0 mil), as duas maiores cidades em termos populacionais. Em termos relativos, no entanto, São João da Barra viu oito em cada dez migrantes chegarem recentemente, reflexo das mudanças que vem passando com os investimentos em energia e logística.

Ao se analisar a evolução da atividade econômica, pela observação do volume de renda, derivado dos fluxos líquidos intermunicipais (VAF) ou da geração de negócios (ICMS), associada às mudanças populacionais, particularmente das indicações da migração interna no estado do Rio de Janeiro, elegem-se algumas regiões que aparentam responder a estímulos específicos ou combinados. No que se referem a processos econômicos, as regiões do Médio Paraíba e a do Norte Fluminense; à combinação de estímulo econômico e oferta de opções turísticas, lazer e residência, a da Costa Verde, e; a das Baixadas Litorâneas, como aquela que reage basicamente à mobilidade populacional, haja vista que apresentou perda na geração do VAF, mas obteve melhoria na geração de negócios (ICMS).

$\mathrm{O}$ aumento da renda e dos negócios locais nas regiões que vem recebendo investimentos há alguns anos, por seu turno, se manifestou segundo as proposições de Keynes e Kalecki, e a migração populacional é prova dos efeitos que a atratividade exerce sobre as decisões das famílias, em busca de melhores alternativas. No entanto, dado que as oportunidades de inserção laboral não são semelhantes para todos, e que a segmentação do mercado de trabalho é um fato, importa saber se houve melhoria no nível de emprego, na qualidade do emprego, com base na distribuição das formas de inserção no mercado de trabalho e na estrutura de salários pagos aos trabalhadores nas distintas regiões. A partir da evolução destas variáveis, será possível confirmar se os trabalhadores se apropriaram dos benefícios que a evolução da atividade econômica proporcionou. 


\subsection{Mercado de trabalho regional: crescimento dos vínculos, formas de inserção e distribuição dos salários pagos}

A maior atratividade de algumas das regiões fluminenses, ocasionada por melhoria da atividade econômica, levou a que a mobilidade populacional pressionasse seus mercados de trabalho, alterando a condição em que se encontrava em 2000. Com base em indicadores de oferta e demanda de trabalho, leituras recentes (MEDEIROS JUNIOR, 2012b) apontaram que as regiões que receberam investimentos industriais, tais como a do Médio Paraíba e a Norte Fluminense, passaram a sofrer efeitos parecidos aos vividos pela região mais desenvolvida do estado (Metropolitana), face às possibilidades de inserção laboral. Na do Médio Paraíba se observou aumento da oferta, enquanto a demanda de trabalho se manteve nos níveis médios do estado, e a Norte Fluminense, que apresentava um quadro de oferta e demanda baixas, passou a uma condição desconfortável de elevada demanda por mão de obra e baixa oferta de profissionais. Nas demais regiões que apresentaram elevada migração populacional, a das Baixadas Litorâneas demonstrou sofrer os efeitos de elevada oferta de trabalho num quadro de demanda insuficiente, e a Costa Verde se encontra em situação confortável, sem pressões excessivas, na medida em que o aumento da oferta tem sido plenamente atendido pela demanda por trabalho.

Tabela 3

Número e participação de vínculos formais em 31/12 e taxa de desocupação nas Regiões de Governo do Estado do Rio de Janeiro - 2000/2010

\begin{tabular}{|c|c|c|c|c|c|c|}
\hline \multirow[t]{2}{*}{ Estado e Regiões de Governo } & \multicolumn{2}{|c|}{ Vínculos formais $\left(\mathrm{n}^{\circ}\right)$} & \multicolumn{2}{|c|}{$\begin{array}{l}\text { Participação do } \\
\text { número de vínculos } \\
\text { formais }(\%)\end{array}$} & \multicolumn{2}{|c|}{$\begin{array}{c}\text { Taxa de desocupação } \\
(\%)\end{array}$} \\
\hline & 2000 & 2010 & 2000 & 2010 & 2000 & 2010 \\
\hline Estado do Rio de Janeiro & 2724012 & 4086424 & 100.0 & 100.0 & 17.1 & 8.5 \\
\hline Região Metropolitana & 2194624 & 3151210 & 80.6 & 77.1 & 17.8 & 8.6 \\
\hline Região Noroeste Fluminense & 30760 & 50820 & 1.1 & 1.2 & 10.8 & 7.8 \\
\hline Região Norte Fluminense & 103228 & 231073 & 3.8 & 5.7 & 14.4 & 9.3 \\
\hline Região Serrana & 126395 & 180780 & 4.6 & 4.4 & 12.5 & 5.8 \\
\hline Região das Baixadas Litorâneas & 69917 & 156466 & 2.6 & 3.8 & 15.8 & 9.7 \\
\hline Região do Médio Paraíba & 135872 & 196160 & 5.0 & 4.8 & 17.5 & 8.6 \\
\hline Região Centro-Sul Fluminense & 38972 & 63027 & 1.4 & 1.5 & 15.6 & 8.7 \\
\hline Região da Costa Verde & 24244 & 56888 & 0.9 & 1.4 & 18.4 & 7.8 \\
\hline
\end{tabular}

Fonte: Ministério do Trabalho e Emprego; IBGE, Censos Demográficos. 
Apesar do estado dos mercados de trabalho ter se tornado mais difícil em algumas regiões, houve, no total do estado, um acréscimo de 50,0\% mais postos de trabalho (1,4 milhão de novas vagas), com destaque para a região Metropolitana em termos absolutos (957 mil postos), mas a taxa inferior (43,6\%) à das demais, o que a fez perder participação (Tabela 3). Em termos relativos, o maior crescimento foi na região da Costa Verde, que apesar de abrir menos postos de trabalho que outras (33 mil), mais que dobrou o número de vagas $(134,6 \%)$. Ao se analisar algumas das cidades que mais se sobressaíram neste indicador, surgem dentre elas, as que vêm sendo destacadas neste texto: Macaé (3,0 vezes mais postos) e São João da Barra $(2,8)$ no Norte Fluminense; Rio das Ostras $(5,2)$, Saquarema (3,8), Casimiro de Abreu $(2,5)$ e Armação dos Búzios $(2,4)$ nas Baixadas Litorâneas; Porto Real $(5,6)$ no Médio Paraíba e; Angra dos Reis $(2,4)$, Mangaratiba $(2,3)$ e Paraty $(2,0)$ na Costa Verde.

Os benefícios da maior absorção de mão de obra, combinado com taxas de crescimento populacional, relativamente, estáveis, levou a que o desemprego caísse à metade no estado do Rio de Janeiro entre 2000 e 2010, mas o mesmo não se deu para algumas das regiões mais dinâmicas, nas quais, apesar da redução, as taxas se apresentam superiores à média. Os casos mais explícitos são os das regiões Norte Fluminense e das Baixadas Litorâneas, cujo desemprego era inferior ao do estado em 2000 (14,4\% na primeira e 15,8\% na segunda, contra 17,1\%), e que em 2010 se situava acima dele $(9,3 \%$ e 9,7\%, contra 8,5\%). Estas mesmas regiões foram reportadas como as que tiveram mudanças de estado do mercado de trabalho mais críticas, mesmo que por motivos diversos.

Resta considerar se o dinamismo que até aqui tem se manifestado em algumas das regiões em estudo, reverteram em benefício dos trabalhadores locais, quanto à melhoria da inserção no mercado, e à distribuição dos salários pagos. Para o primeiro indicador, com base nas categorias disponíveis nos Censos Demográficos, é possível avaliar, se a condição em que os trabalhadores se inseriram, caminhou na direção de maior formalidade, o que lhes garantiria acesso aos benefícios da legislação.

De acordo com os resultados em ambos os Censos, houve melhoria da qualidade do emprego existente no estado do Rio de Janeiro, na medida em que a participação de 
trabalhadores em relações formais ${ }^{8}$ elevou-se de 54,6\% em 2000 para 61,6\% (Tabela 4). Este movimento se deveu, principalmente, à maior participação do contingente de empregados com carteira assinada, haja vista a estabilidade dos militares e funcionários públicos estatutários na distribuição, e a queda de empregadores.

No que se refere ao comportamento das regiões, algumas características se revelam na comparação entre os períodos de tempo. A primeira é a de que, no nível das categorias, houve maior redução "dos sem carteira" do que "dos conta própria", provavelmente em razão da passagem dos primeiros à condição de carteira assinada. Este movimento se deve, em parte, aos esforços que vem sendo empreendidos, quanto à maior fiscalização, e por outro, ao crescimento e à consolidação das atividades econômicas de apoio às empresas, que exige maior grau de formalização dos empreendimentos e das relações de trabalho.

\footnotetext{
${ }^{8}$ Aqui considerados os empregos com carteira assinada, militares e funcionários públicos estatutários e os empregadores.
} 
Tabela 4

Participação dos empregados segundo a posição na ocupação no mercado de trabalho nas Regiões de Governo do Estado do Rio de Janeiro - 2000/2010

\begin{tabular}{|c|c|c|c|c|c|}
\hline Estado e Regiões de Governo & $\begin{array}{c}\text { Empregados } \\
\text { com carteira } \\
\text { assinada }\end{array}$ & $\begin{array}{c}\text { Militares e } \\
\text { funcionários } \\
\text { públicos } \\
\text { estatutários }\end{array}$ & $\begin{array}{c}\text { Empregados } \\
\text { sem carteira } \\
\text { assinada }\end{array}$ & Conta própria & $\begin{array}{c}\text { Empregado- } \\
\text { res }\end{array}$ \\
\hline \multicolumn{6}{|l|}{2000} \\
\hline Estado do Rio de Janeiro & 45.3 & 6.2 & 23.2 & 22.2 & 3.1 \\
\hline Região Metropolitana & 46.7 & 6.6 & 21.8 & 21.9 & 3.1 \\
\hline Região Noroeste Fluminense & 32.7 & 6.3 & 35.9 & 22.1 & 2.8 \\
\hline Região Norte Fluminense & 39.1 & 5.6 & 29.5 & 23.4 & 2.5 \\
\hline Região Serrana & 42.7 & 4.1 & 24.2 & 25.1 & 3.9 \\
\hline Região das Baixadas Litorâneas & 32.7 & 6.2 & 31.8 & 26.2 & 3.2 \\
\hline Região do Médio Paraíba & 56.7 & 4.6 & 19.7 & 16.7 & 2.4 \\
\hline Região Centro-Sul Fluminense & 42.8 & 5.3 & 27.6 & 21.3 & 3.0 \\
\hline Região da Costa Verde & 38.8 & 4.7 & 29.6 & 23.5 & 3.3 \\
\hline \multicolumn{6}{|l|}{2010} \\
\hline Estado do Rio de Janeiro & 53.6 & 6.1 & 18.0 & 20.4 & 1.9 \\
\hline Região Metropolitana & 54.9 & 6.3 & 17.0 & 19.9 & 1.9 \\
\hline Região Noroeste Fluminense & 40.2 & 7.3 & 29.1 & 21.6 & 1.9 \\
\hline Região Norte Fluminense & 52.2 & 5.6 & 20.2 & 20.6 & 1.3 \\
\hline Região Serrana & 48.8 & 4.4 & 19.1 & 25.0 & 2.8 \\
\hline Região das Baixadas Litorâneas & 41.6 & 7.8 & 23.8 & 24.5 & 2.3 \\
\hline Região do Médio Paraíba & 59.0 & 4.4 & 16.7 & 18.1 & 1.9 \\
\hline Região Centro-Sul Fluminense & 49.1 & 6.0 & 23.4 & 19.4 & 2.1 \\
\hline Região da Costa Verde & 54.4 & 5.5 & 19.0 & 19.3 & 1.9 \\
\hline
\end{tabular}

Por outro lado, quanto "aos conta própria", as maiores participações em 2010 ocorreram na região Serrana, que praticamente se manteve em relação a 2000, apesar do maior contingente de empregados com carteira, e na região das Baixadas Litorâneas, com pequena redução, e que como mencionado anteriormente, tem seu mercado de trabalho em situação desconfortável. Assim, enquanto na primeira a estabilidade pode ser uma prática comum, na segunda aparenta ser uma alternativa às condições adversas.

A segunda característica refere-se à condição das regiões que receberam investimentos industriais, mais dinâmicas. Enquanto no Médio Paraíba já se observava elevada participação de relações formais em 2000 (63,6\%), e que aumentaram em 2010, $(65,3 \%)$, nas regiões Norte Fluminense e Costa Verde predominavam relações 
informais $^{9}$ (52,9\% e 53,1\%, respectivamente), o que indica que o crescimento da atividade econômica local foi mais recente, ancorada na maturação e continuidade dos investimentos e em razão dos efeitos decorrentes da expansão dos serviços de apoio às empresas e às famílias. Mesmo que este quadro tenha se revertido $(59,2 \%$ e $61,8 \%$ em 2010, respectivamente), não há região que ofereça melhores condições de ingresso no mercado de trabalho do que a do Médio Paraíba, para aqueles cuja capacitação seja adequada às suas necessidades.

Por fim, e para avaliar se houve melhoria nos níveis salariais como resposta ao crescimento da atividade econômica e das condições de inserção ocupacional, a remuneração dos trabalhadores será distribuída em estratos de salários mínimos nos dois momentos do tempo, para que se observe como se comportam os mercados de trabalho regionais. Esta proposição não permite comparações diretas entre os estratos em razão, da política de valorização do salário mínimo, implementada pelo governo federal desde 2002, haja vista o aumento real de aproximadamente 70\%. Portanto, apesar dos estratos serem os mesmos, não há como compará-los no tempo, nem “descontar” a variação real, para que ambas as distribuições se assemelhem ${ }^{10}$.

Com base na distribuição dos rendimentos, obtida na RAIS/MTE, nos dois pontos do tempo (Tabela 5), se poderia afirmar que houve aumento no número de trabalhadores formais que recebiam até três salários mínimos entre 2000 e 2010 no estado do Rio de Janeiro, o que representaria piora da distribuição, mas na medida em que o salário mínimo de enquadramento em 2010 é aproximadamente $70 \%$ superior ao de 2000, o primeiro estrato estaria capturando trabalhadores que ocupariam estratos superiores a ele.

Outra opção de análise, ainda com base em comparações entre as distribuições, seria considerar que, mesmo com um indexador que distorça a distribuição e os estratos mais altos, apresentassem aumento de participação, de fato teria havido melhoria significativa na remuneração dos empregados em cargos mais elevados. Mesmo que haja desvio no enquadramento, seus rendimentos seriam consideravelmente diferentes

\footnotetext{
${ }^{9}$ Empregados sem carteira assinada e conta própria.

${ }^{10} \mathrm{O}$ propósito foi observar a distribuição dos rendimentos informados na RAIS, que cobre basicamente duas das categorias da posição na ocupação analisadas neste trabalho (empregados com carteira assinada e militares e funcionários públicos estatutários), mas as variáveis disponíveis naquele registro administrativo nos dois pontos do tempo não permite comparar valores nominais diretamente.
} 
das demais. Neste caso, apenas a região Norte Fluminense teria apresentado melhoria, e só no estrato de dez ou mais salários mínimos.

\section{Tabela 5}

Participação dos empregados segundo as classes de salários mínimos nas Regiões de Governo do Estado do Rio de Janeiro - 2000/2010

\begin{tabular}{l|r|r|r|r}
\hline Estado e Regiões de Governo & $\begin{array}{c}\text { Até três } \\
\text { salários } \\
\text { mínimos }\end{array}$ & $\begin{array}{c}\text { De três a } \\
\text { cinco salários } \\
\text { mínimos }\end{array}$ & $\begin{array}{c}\text { De cinco a } \\
\text { dez salários } \\
\text { mínimos }\end{array}$ & $\begin{array}{c}\text { Mais de dez } \\
\text { salários } \\
\text { mínimos }\end{array}$ \\
\hline 2000 & & & & \\
Estado do Rio de Janeiro & 49.4 & 20.4 & 18.0 & 11.8 \\
Região Metropolitana & 46.0 & 21.0 & 19.4 & 13.2 \\
Região Noroeste Fluminense & 81.1 & 11.7 & 4.7 & 2.3 \\
Região Norte Fluminense & 61.0 & 17.3 & 13.4 & 7.8 \\
Região Serrana & 65.5 & 17.4 & 11.8 & 5.1 \\
Região das Baixadas Litorâneas & 69.9 & 17.0 & 10.0 & 2.9 \\
Região do Médio Paraíba & 57.0 & 19.1 & 14.9 & 8.9 \\
Região Centro-Sul Fluminense & 73.5 & 15.1 & 8.5 & 2.7 \\
Região da Costa Verde & 51.4 & 20.9 & 16.8 & 10.6 \\
& & & & \\
2010 & & & & \\
Estado do Rio de Janeiro & 68.4 & 13.2 & 9.9 & 6.8 \\
Região Metropolitana & 66.5 & 13.6 & 10.7 & 7.5 \\
Região Noroeste Fluminense & 88.3 & 7.0 & 2.7 & 0.8 \\
Região Norte Fluminense & 60.5 & 14.3 & 11.8 & 12.0 \\
Região Serrana & 84.3 & 8.8 & 4.5 & 1.1 \\
Região das Baixadas Litorâneas & 80.9 & 9.8 & 5.6 & 2.1 \\
Região do Médio Paraíba & 75.5 & 13.2 & 6.8 & 2.8 \\
Região Centro-Sul Fluminense & 85.5 & 8.1 & 3.8 & 1.1 \\
Região da Costa Verde & 62.2 & 17.3 & 11.3 & 6.9 \\
\hline Fonte: Ministério do Trabalho Emprego & & & & \\
\end{tabular}

Fonte: Ministério do Trabalho e Emprego.

Abandonando-se as comparações intertemporais e tomando a distribuição em 2010 como referência para o modo como se comportam os mercados de trabalho locais, considerando-se os custos atuais exigidos para a absorção de trabalhadores, o que se depreende é que, das oito regiões estudadas, apenas a Metropolitana, a Norte Fluminense e a da Costa Verde superariam a distribuição média do estado do Rio de Janeiro. São as que melhor remuneram seus trabalhadores, mas, das três, a que oferece o maior retorno é a Norte Fluminense, na medida em que possui, em termos relativos, 
maior contingente de empregados com remuneração entre cinco a dez, e mais de dez salários mínimos.

Na medida em que uma das questões que motivam a migração é o diferencial entre os salários do destino e da origem, é razoável supor que, não só aqueles que migraram diretamente para a principal cidade da região Norte Fluminense (Macaé), como os que optaram pelas cidades vizinhas a ela (Carapebus e Quissamã, a nordeste) ,na mesma região, ou para o território limítrofe desta, com a das Baixadas Litorâneas (Rio das Ostras, Casimiro de Abreu, Cabo Frio e Armação dos Búzios, a sudoeste), pode ter decidido a partir do diferencial observado.

\subsection{Produto interno bruto regional: interiorização e manutenção da tendência de maior participação das regiões industriais}

A geração de riqueza nas regiões fluminenses em 2010 demonstrou que, comparativamente à distribuição em 2000, se manteve o quadro de desconcentração, com perda de participação da região Metropolitana e ganhos nas demais. Em 2000, $74,4 \%$ do valor adicionado bruto (VAB) do estado foi gerado na área Metropolitana, contra 26,6\% no "interior"; dez anos depois, quase dez pontos percentuais a mais na participação do $\operatorname{VAB}(35,2 \%)$ foram computados no "interior". Dentre as regiões interioranas, as responsáveis pelo ganho foram a Norte Fluminense com 5,1 pontos percentuais (pp) a mais, a das Baixadas Litorâneas (+2,0 pp), Costa Verde $(+1,9$ pp), Médio Paraíba $(+0,6$ pp) e Serrana $(+0,1$ pp). As duas regiões restantes, Noroeste Fluminense e Centro-Sul Fluminense, registraram perdas que, a exemplo do ganho da região Serrana, se caracterizou mais por manutenção da participação.

Se considerados os setores econômicos divulgados pelo IBGE, nas regiões que agregaram mais pontos percentuais na participação em relação ao VAB do estado do Rio de Janeiro, a indústria foi determinante, com $+9,4$ pp na Norte Fluminense e $+3,2$ pp na das Baixadas Litorâneas, enquanto os serviços influenciaram o acréscimo na Costa Verde, com $+2,4$ pp. O resultado dos acréscimos na participação do VAB e dos setores econômicos foi que a região Norte Fluminense consolidou-se como a segunda maior do estado, com 12,5\%, cinco pontos percentuais a mais do que a terceira colocada, a do Médio Paraíba (7,4\%). 


\section{Tabela 6}

Valor adicionado bruto total e dos setores econômicos, e participação do valor adicionado bruto total e dos setores econômicos segundo as Regiões de Governo do Estado do Rio de Janeiro - 2010

\begin{tabular}{|c|c|c|c|c|}
\hline Estado e Regiões de Governo & Total & Agropecuária & Indústria & Serviços \\
\hline \multicolumn{5}{|l|}{ Valor (1000 R\$) } \\
\hline Estado do Rio de Janeiro & 344405425 & 1449018 & 96617936 & 246338471 \\
\hline Região Metropolitana & 223251952 & 217436 & 39431400 & 183603117 \\
\hline Região Noroeste Fluminense & 3610191 & 154706 & 528399 & 2927086 \\
\hline Região Norte Fluminense & 43134222 & 292363 & 27759048 & 15082811 \\
\hline Região Serrana & 14214953 & 364184 & 3951187 & 9899582 \\
\hline Região das Baixadas Litorâneas & 20312962 & 123878 & 10304438 & 9884647 \\
\hline Região do Médio Paraíba & 25482460 & 141195 & 11701429 & 13639835 \\
\hline Região Centro-Sul Fluminense & 3896536 & 106214 & 788702 & 3001620 \\
\hline Região da Costa Verde & 10502148 & 49041 & 2153333 & 8299773 \\
\hline \multicolumn{5}{|l|}{ Participação (\%) } \\
\hline Estado do Rio de Janeiro & 100.0 & 0.4 & 28.1 & 71.5 \\
\hline Região Metropolitana & 100.0 & 0.1 & 17.7 & 82.2 \\
\hline Região Noroeste Fluminense & 100.0 & 4.3 & 14.6 & 81.1 \\
\hline Região Norte Fluminense & 100.0 & 0.7 & 64.4 & 35.0 \\
\hline Região Serrana & 100.0 & 2.6 & 27.8 & 69.6 \\
\hline Região das Baixadas Litorâneas & 100.0 & 0.6 & 50.7 & 48.7 \\
\hline Região do Médio Paraíba & 100.0 & 0.6 & 45.9 & 53.5 \\
\hline Região Centro-Sul Fluminense & 100.0 & 2.7 & 20.2 & 77.0 \\
\hline Região da Costa Verde & 100.0 & 0.5 & 20.5 & 79.0 \\
\hline
\end{tabular}

Fonte: IBGE, Contas regionais 2012, Produto Interno Bruto dos Municípios 2012; Fundação CEPERJ.

Ainda, quanto à distribuição do VAB pelas atividades econômicas nas regiões, no ano de 2010 (Tabela 6), é possível destacar a presença dos setores em cada uma das regiões, apesar dos serviços participarem com mais da metade da maioria delas. $\mathrm{O}$ setor agropecuário é mais presente nas regiões Noroeste Fluminense, Serrana e Centro-Sul Fluminense; a indústria participa com maior expressividade nas regiões Norte Fluminense, das Baixadas Litorâneas e do Médio Paraíba, e; por exclusão, os serviços predominam nas regiões Metropolitana e da Costa Verde. 


\section{Considerações finais}

Keynes e Kalecki defenderam os investimentos como dinamizadores da atividade econômica, gerando ganhos de renda e emprego, num círculo virtuoso, que alimentaria os negócios a ponto de gerar novos estímulos e investimentos. Se trazidas as proposições teóricas para o território, em razão da atratividade das áreas que demonstrassem reagir nos moldes propostos, a mobilidade populacional geral e da força de trabalho se estabeleceria, levando a que a possibilidade de retornos maiores do que os oferecidos na origem norteassem as decisões.

De acordo com as indicações decorrentes das leituras empreendidas neste trabalho, pode-se afirmar que, no território fluminense se confirmaram as proposições teóricas keynesianas e kaleckianas, haja vista que as regiões que receberam, e continuam recebendo investimentos, apresentaram ganhos de participação no valor adicionado fiscal, na arrecadação do ICMS, e abriram novos postos de trabalho, em detrimento daquelas que não foram alcançadas por inversões.

Dentre as regiões mais dinâmicas, particularmente a Norte Fluminense foi a que mais se destacou no período intercensitário, recebendo migrantes que vieram usufruir dos benefícios da prosperidade econômica, e também da possibilidade de inserção no mercado de trabalho, condição já há muito oferecida no Médio Paraíba, bem como de auferir remuneração superior à das outras. O circulo econômico virtuoso trouxe como resultado a consolidação de segunda maior região do estado em geração de riquezas (PIB), bem como, quanto ao VAB industrial $(28,7 \%$, contra $40,1 \%$ na região Metropolitana), confirmando a tendência de desconcentração regional fluminense, determinada por investimentos industriais.

Para a confirmação da tendência observada, no entanto, tomou-se como referência informações estruturais disponibilizadas com defasagem média de dois anos (o PIB estadual e municipal chega a quase três anos). De acordo com o comportamento regional apresentado, no momento da realização deste trabalho, provavelmente, já há maior aprofundamento, ou, devido a outros processos que possam ter alterado a tendência até então dominante, outras regiões demonstram novos caminhos, que só serão conhecidos daqui a dois anos. 
Considerando que, para fins de planejamento regional, ter informações com periodicidade menor é insumo necessário, esforços pela melhor disponibilização de dados permitiria leituras menos espaçadas no tempo. Além disso, e dado que a desconcentração regional fluminense caminha para alguns espaços específicos do interior, ter informações em tempo menor, e com recorte regional, seria de grande valia. Em termos espaciais, por outro lado, seria valioso contar com informações conjunturais regionais, que permitissem antecipar e/ou confirmar tendências.

Como exemplo, há informações disponíveis no Ministério do Trabalho e Emprego sobre demanda por trabalho no nível municipal e no recorte de interesse (por atividade, gênero, instrução etc.), que permitem a geração de modelos para fins de previsão (MEDEIROS JUNIOR, 2009b, 2010a, 2010b). Regionalmente, acrescida de indicadores locais (arrecadação do ISSQN etc.), possibilitaria o monitoramento da economia local/regional, tornando-se ferramenta útil para o gestor municipal/regional planejar políticas públicas para o enfrentamento das condições provocadas pelo capital no território, permitindo-lhe antecipar os efeitos que deslocamentos espaciais da força de trabalho possam proporcionar.

Portanto, avançar na agenda de melhor estruturação das bases de dados municipais, regionais e estaduais, seria de grande valia para todos aqueles que se interessam pelo desenvolvimento do estado do Rio de Janeiro.

\section{Referências Bibliográficas:}

BORJAS, G.J.. Economia do trabalho. 5. ed. Porto Alegre: AMGH, 2012.

BRAGA, R. Dinâmica econômica e dinâmica demográfica: uma avaliação da Região Metropolitana de Campinas-SP-Brasil. Revista Geográfica de América Central, número especial, EGAL, Costa Rica. 2011. Disponível em: www.revistas.una.ac.cr/index.php/geografica/article/view/2195. Acesso em: 17 set. 2012.

CARVALHO, P.M. Dinâmica econômica e mobilidade populacional: o caso de SP. Graduação em Ciências Econômicas (monografia). Taubaté: UNITAU, 2003. 
FUNDAÇÃO CEPERJ. Anuário estatístico do Rio de Janeiro 2010. Rio de Janeiro, 2011. 1 CD-ROM.

Estado do Rio de Janeiro: um breve balanço da década. Rio de Janeiro, [2012]. 26 p. Disponível em: http://www.ceperj.rj.gov.br/. Acesso em: 10 jul. 2012.

Produto interno bruto dos municípios - 2010: Estado do Rio de Janeiro, 2012.

Disponível em: http://www.ceperj.rj.gov.br/ceep/pib/PIB_municipios_RJ_2010.pdf. Acesso em: 3 jan. 2012.

HOFFMAN, M.B.P.; CUTRIM, M.A.B. A classificação da condição de atividade na PED. São Paulo em Perspectiva, v. 20, n. 4, p. 18-35, out./dez. 2006, São Paulo, Fundação Seade, 2006. Disponível em: http://www.seade.gov.br; http://www.scielo.br.

KALECKI, M. Teoria da dinâmica econômica: ensaio sobre as mudanças cíclicas e a longo prazo da economia capitalista. São Paulo: Nova Cultural, 1985.

KEYNES, J.M. A teoria geral do emprego, do juro e da moeda. São Paulo: Nova Cultural, 1988.

LIMA, R. Mercado de trabalho: o capital humano e a teoria da segmentação. Pesquisa e Planejamento Econômico, v. 10, n. 1, abr. 1980, Rio de Janeiro, IPEA, 1980.

MEDEIROS JUNIOR, H.. Mercado de trabalho sinaliza recuperação em 2003. In: NATAL, J. L. A. (Org.) Conjuntura fluminense recente (1998-2004): memórias selecionadas, 1 ed. , v. 1, p. 250-253, Rio de Janeiro: Papel Virtual, 2004.

Onde ocorre a recuperação do mercado de trabalho: na capital ou no interior? In: NATAL, J. L. A. (Org.) Conjuntura fluminense recente (1998-2004): memórias selecionadas, 1 ed. , v. 1, p. 250-253, Rio de Janeiro: Papel Virtual, 2004.

A capital voltará a ditar o ritmo do emprego em 2005? Revista de Economia Fluminense, n. 3, p. 32-35, maio 2005, Rio de Janeiro, 2005.

O papel das cidades e a realidade municipal fluminense: métricas $e$ indicadores para planejamento. In: XV SEMANA IPPUR: Espaço e vida pública, território, imaginário, poder, 2009, Rio de Janeiro. SEMANA IPPUR, 15. Rio de Janeiro, UFRJ/IPPUR, 2009. 1 CD-ROM. 
Previsão do nível de emprego e política pública na cidade do Rio de Janeiro. São Paulo em Perspectiva, v. 23, n. 2, p. 100-108, jul./dez. 2009, São Paulo, Fundação Seade, 2009. Disponível em: www.seade.gov.br; www.scielo.br.

Os mercados de trabalho carioca e metropolitano fluminenses estão em situação de incerteza. In: NATAL, Jorge L. A.. (Org.). Conjuntura fluminense recente 2: memórias selecionadas 2004-2008. 1 ed., v. 1, p. 231-236, Rio de Janeiro: J. Natal, 2009.

- O cenário econômico não beneficia os mercados de trabalho carioca e metropolitano fluminense. In: NATAL, Jorge L. A.. (Org.). Conjuntura fluminense recente 2: memórias selecionadas 2004-2008, 1 ed., v. 1, p. 240-245, Rio de Janeiro: J. Natal, 2009.

A produtividade fabril fluminense cresce sem benefícios à ocupação industrial. In: NATAL, Jorge L. A.. (Org.). Conjuntura fluminense recente 2: memórias selecionadas 2004-2008. 1 ed., v. 1, p. 222-225, Rio de Janeiro: J. Natal, 2009.

A política monetária compromete o equilíbrio instável do mercado de trabalho fluminense. In: NATAL, Jorge L. A.. (Org.). Conjuntura fluminense recente 2: memórias selecionadas 2004-2008. 1 ed., v. 1, p. 207-213, Rio de Janeiro: J. Natal, 2009.

A rotatividade do posto de trabalho e o diferencial de salários inibem a melhoria dos rendimentos. In: NATAL, Jorge L. A.. (Org.). Conjuntura fluminense recente 2: memórias selecionadas 2004-2008. 1 ed., v. 1, p. 195-201, Rio de Janeiro: J. Natal, 2009.

A capital voltará a ditar o ritmo do emprego em 2005?. In: NATAL, Jorge L.

A.. (Org.). Conjuntura fluminense recente 2: memórias selecionadas 2004-2008. 1 ed., v. 1, p. 188-194, Rio de Janeiro: J. Natal, 2009.

O crédito e a renda sustentarão o emprego fluminense?. In: NATAL, Jorge L. A.. (Org.). Conjuntura fluminense recente 2: memórias selecionadas 2004-2008. 1 ed., v. 1, p. 181-187, Rio de Janeiro: J. Natal, 2009.

Até quando vão as boas notícias do mercado de trabalho fluminense em 2004?. In: NATAL, Jorge L. A.. (Org.). Conjuntura fluminense recente 2: memórias 
selecionadas 2004-2008. 1 ed., v. 1, p. 167-180, Rio de Janeiro: J. Natal, 2009. Previsão e planejamento: antecipando a tendência do emprego formal na cidade do Rio de Janeiro. Coleção Estudos Cariocas, v. 10, n. 20100401, p. 1-31, Rio de Janeiro, Instituto Municipal de Urbanismo Pereira Passos, 2010.

Previsão do nível de emprego e política pública na cidade do Rio de Janeiro. In: ENCONTRO NACIONAL DE ESTUDOS POPULACIONAIS, 17., 2010, Caxambu. Anais... Caxambu, ABEP, 2010. 1 CD-ROM.

Mudanças de estado do mercado de trabalho fluminense: diferenças regionais entre 2000 e 2010. In: ENCONTRO NACIONAL DE ESTUDOS POPULACIONAIS, 18., 2012, Águas de Lindóia. Anais... Águas de Lindóia, ABEP, 2012. 1 CD-ROM.

Dinâmica econômica e o mercado de trabalho fluminense entre 2000 e 2010. In: SEMINÁRIO DINÂMICA ECONÔMICA E DESENVOLVIMENTO REGIONAL, 1., 2012, Uberaba. Anais... Uberaba, UNIVERSIDADE FEDERAL DO TRIÂNGULO MINEIRO, 2012. 1 CD-ROM.

MEDEIROS JUNIOR, H.; GRAND JUNIOR, J. Distribuição dos empregos formais na cidade do Rio de Janeiro: uma análise exploratória. In: SEMANA IPPUR: um território em disputa, 16., 2010, Rio de Janeiro, Anais... Rio de Janeiro, UFRJ/IPPUR, $2010 . \quad$ Disponível em: http://www.ippur.ufrj.br/download/semana_pur_2010/completos/helcio_joao.pdf.

Geografia econômica regional fluminense nos anos 00: aumento de riqueza, expectativa de pobreza. In: ENCONTRO DA ANPUR: quem planeja o território? Atores, arenas e estratégias, 14., 2011, Rio de Janeiro. Anais... Rio de Janeiro, ANPUR, 2011. 1 CD-ROM

Distribuição dos empregos formais na cidade do Rio de Janeiro: uma análise espacial. In: ENCONTRO DA ANPUR: quem planeja o território? Atores, arenas e estratégias, 14., 2011, Rio de Janeiro. Anais... Rio de Janeiro, ANPUR, 2011. 1 CDROM 
. Distribuição dos empregos formais na cidade do Rio de Janeiro em 2008: uma análise espacial. Coleção Estudos Cariocas, v. 11, n. 20110101, p. 1-26, Rio de Janeiro, Instituto Municipal de Urbanismo Pereira Passos, 2011.

MEDEIROS JUNIOR, H.; MEDINA, M.H.; GRAND JUNIOR, J. Nível de emprego carioca apresenta sinais de recuperação em abril de 2009. Notas conjunturais IPP, n. 1, maio 2009, Rio de Janeiro, Instituto Municipal de Urbanismo Pereira Passos, 2009.

MELO, H.P.; CONSIDERA, C.M. Industrialização fluminense - 1930-1980. Revista do Rio de Janeiro, v. 1, n. 3, UFF, Niterói, 1986.

NATAL, Jorge L.A. O Estado do Rio de Janeiro pós-1995: dinâmica econômica, rede urbana e questão social. Rio de Janeiro: Pubblicati, 2005.

OLIVEIRA, A. Território e mercado de trabalho: discursos \& teorias, São Paulo: Editora UNESP, 2006.

Conhecendo o interior paulista: o papel do espaço na dinâmica do mercado de trabalho. São Paulo em Perspectiva, v. 20, n. 4, p. 127-142, out./dez. 2006, São Paulo, Fundação Seade, 2006. Disponível em: http://www.seade.gov.br; http://www.scielo.br.

OLIVEIRA, F.J.G. Reestruturação produtiva: território e poder no Estado do Rio de Janeiro. Rio de Janeiro: Garamond, 2008.

PIQUET, R.P.S. Reestruturação do espaço regional e urbano no Brasil: o poder do Estado e dos grandes investimentos. Rio de Janeiro: UFRJ/IPPUR, 1993.

POCHMANN, M. Rumos da política de trabalho no Brasil. In: SILVA, M.O.S.; IAZBECK, M.C. (Org.). Políticas públicas de trabalho e renda no Brasil contemporâneo. 2. ed. São Paulo: Cortez; São Luís: Fapema, 2008.

RAMOS, Lauro. O desempenho recente do mercado de trabalho brasileiro: tendências, fatos estilizados e padrões espaciais. Texto para discussão, n. 1255, Rio de Janeiro, Ipea, 2007.

SILVA, R.D. Rio de Janeiro, crescimento, transformações e sua importância para a economia nacional (1930-2000). Dissertação (mestrado), Campinas, UNICAMP, 2004. Indústria e desenvolvimento regional no Rio de Janeiro (1990-2008). Rio de Janeiro: Editora FGV, 2012. 
SOUZA, M.C.C. Mercado de trabalho: abordagens duais. Revista de Administração de Empresas, v. 18, n. 1, jan./mar. 1978, Rio de Janeiro, FGV, 1978. 